\title{
Myosin light chain phosphorylation facilitates in vivo myosin filament reassembly after mechanical perturbation
}

\author{
by \\ Dake Qi \\ M. D., The Medical College of Shanghai Tiedao University, 1999 \\ A THESIS SUBMITTED IN PARTIAL FULFILMENT OF \\ THE REQUIREMENT FOR THE DEGREE OF \\ MASTER OF SCIENCE \\ in \\ THE FACULTY OF GRADUATE STUDIES \\ (Department of Pharmacology \& Therapeutics) \\ We accept this thesis as conforming \\ to the required standard
}

THE UNIVERSITY OF BRITISH COLUMBIA

March, 2002

(C) Dake Qi, 2002 
In presenting this thesis in partial fulfilment of the requirements for an advanced degree at the University of British Columbia, I agree that the Library shall make it freely available for reference and study. I further agree that permission for extensive copying of this thesis for scholarly purposes may be granted by the head of my department or by his or her representatives. It is understood that copying or publication of this thesis for financial gain shall not be allowed without my written permission.

Department of Pharmacology \& Therapentics

The University of British Columbia Vancouver, Canada

Date April.22, 2002 


\section{ABSTRACT}

It is generally believed that the myosin thick filaments in smooth muscle are structurally less stable than those in striated muscle. In vitro studies have shown that phosphorylation of the $20-\mathrm{kD}$ myosin light chain (MLC) facilitates formation of the thick filaments from monomeric myosins in solution. It appears that the structural integrity of the thick filaments can be enhanced by phosphorylation of the MLC. It is however not known whether the transition from monomeric to filamentous myosin occurs in intact smooth muscle when the light chains are phosphorylated during muscle activation. The physiological significance of the thick filament lability and the role of MLC phosphorylation in modulating the filament integrity in intact smooth muscle are still being debated. It has been shown in our laboratory that mechanical strain is able to induce partial dissolution of unphosphorylated myosin thick filaments in intact smooth muscle; repolymerization of the thick filaments occurs when the muscle is subjected to cycles of contraction and relaxation. The objective of my thesis research is to determine whether MLC phosphorylation is required for repolymerization of the thick filaments after they have been partially disassembled by mechanical agitation.

We used the conventional electron microscopy to quantify the cross-sectional density of myosin thick filaments in airway smooth muscle; partial dissolution of the thick filaments was induced by applying length oscillations to the muscle preparation; recovery of the thick filament density after oscillation was examined in the presence and absence of wortmannin, a potent inhibitor of myosin light chain kinase (MLCK). The results showed that isometric force production in airway smooth muscle was totally 
dependent on MLC phosphorylation. The inhibition of MLC phosphorylation alone did not cause disassembly of myosin filaments. The unphosphorylated thick filaments however partially dissolved when the muscle was subjected to oscillatory strains, as evidenced by a $25 \%$ decrease in the filament density. The post-oscillation filament density did not recover when wortmannin was present; it recovered to the pre-oscillation level when wortmannin was removed. Based on the above findings, we conclude that thick filament formation in vivo is MLC phosphorylation dependent. 


\section{Table of Contents}

Contents

Page

Abstract ii

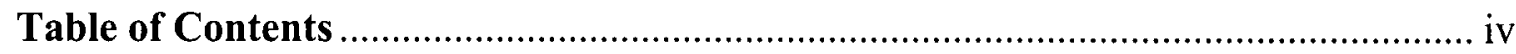

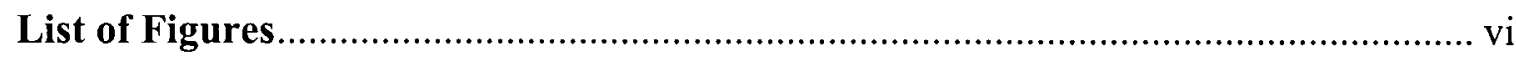

List of Tables .............................................................................................. vii



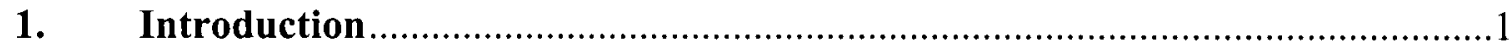

1.1 Mechanism of contraction in smooth muscle ......................................................

1.2 Lability of smooth muscle myosin filaments ......................................................2

1.3 Location of the regulatory light chains on myosin ........................................... 4

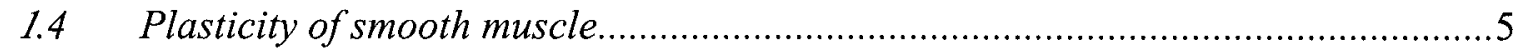



1.6 In vivo studies of myosin filaments ..........................................................

1.7 Pharmacology of wortmannin and its action

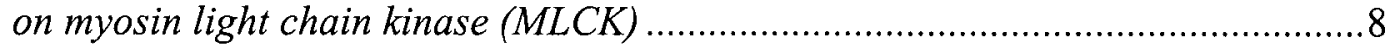



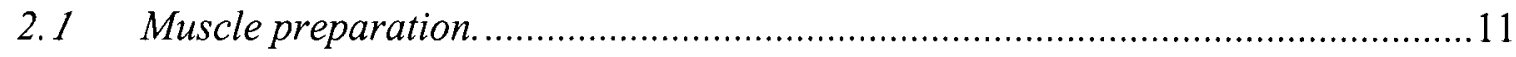

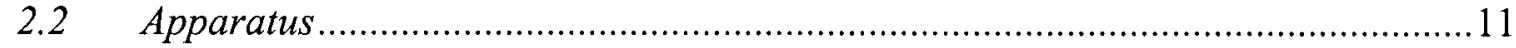

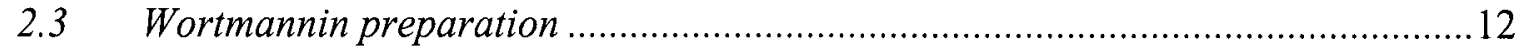



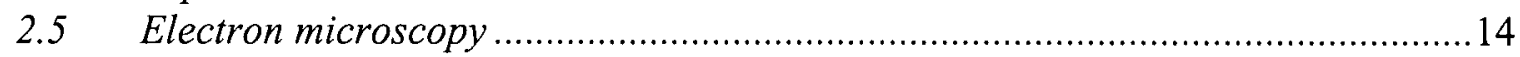

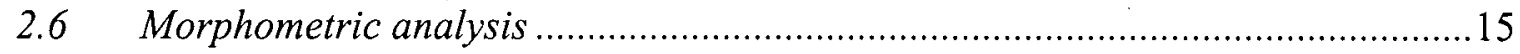

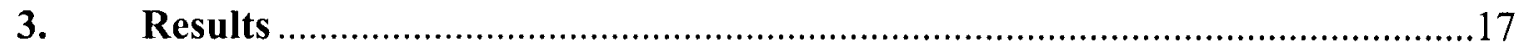

3.1 Effects of wortmannin on the generation of isometric force ...............................17

3.2 Thick filament density in different cell segments ..........................................18

3.3 Effects of wortmannin on cross-sectional density of myosin thick filament ..........18

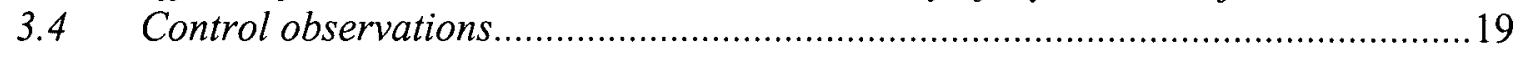




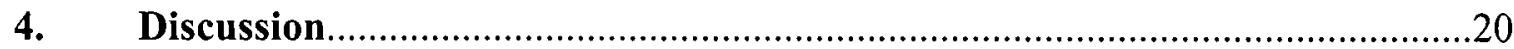

4.1 Effects of wortmannin on intracellular $\mathrm{Ca}^{2+}$ transients .....................................20

4.2 Effect of MLC phosphorylation on

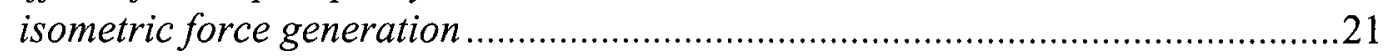

4.3 Reversibility of wortmannin inhibition ...........................................................21

4.4 The relationship between $M L C$ phosphorylation and formation of myosin thick filament .............................................................22

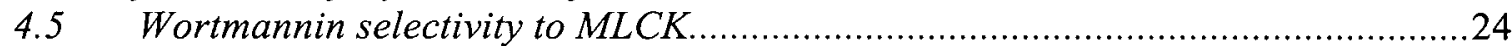

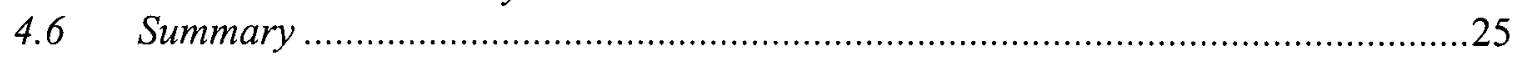

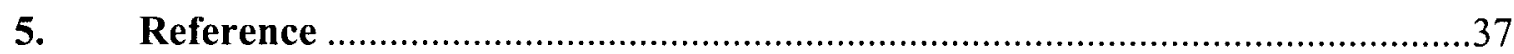




\section{List of Figures}

Fig. 1 Mechanism of smooth muscle activation.

Fig. 2 Location of the regulatory light chains on myosin.

Fig. 3 Electron microscopy of rotary-shadowed $10 S$ and 65 myosin. .28

Fig. 4 Chemical structure of wortmannin and its mechanism of action on MLCK

Fig. 5 Experimental protocol. .30

Fig. 6 The three different intracellular locations

for electron microscopic examination

Fig. 7-A Electron micrograph of muscle fixed at Time 1 (control) .................................32

Fig. 7-B Electron micrograph of muscle fixed at Time 4 .33

Fig. 8 Variation of thick filament density and isometric force under different experimental conditions. 


\section{List of Tables}

\section{Contents}

Page

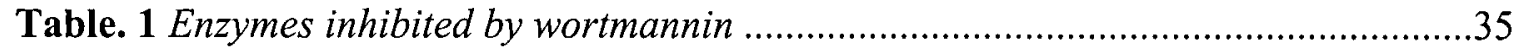

Table. 2 Number of myosin thick filaments

per cell cross-section and cell cross-sectional area .36 


\section{Acknowledgements}

I am very grateful to my supervisor, Dr. Chun Seow, for giving me the opportunity to study and work in his laboratory and for his continuing advice and guidance. I also appreciate Dr. Ernest Puil for his sincere assistance with my study and research. I thank my colleague, Dr. Kuo-Hsing Kuo, for his continuous moral and technical support. Thanks must also be extended to Department of Anatomy in UBC for allowing me to use the electron microscope.

I would like to express my appreciation to the faculty members of the Department of Pharmacology and Therapeutics for their excellent teaching, and to the secretarial staffs, Wynne Leung and Janelle Stewart, without their assistance I would never be able to complete this thesis. The moral supports from my close friends, Drs.Zhen-yuan Xia and Xiang Wan in the department are also important to me.

I must also express my gratitude to the members of my examining committee, Drs. Ismail Laher and Xiaodong Wang for working under the time constraints that were required.

My final gratitude would be kept for my parents. Mere words cannot describe how important they are to me. Without their support, I could never have made it as far as I have. 


\section{Introduction:}

The similarity of force-velocity and length-tension relationships between striated and smooth muscles has led to a conclusion that smooth muscle contraction involves a sliding filament mechanism as that in striated muscle (Fischer, 1944). However, one important difference is that in smooth muscle, the thick filaments are structurally less stable than their counterparts in striated muscle (see review by Bagby, 1983). There is increasing evidence suggesting that thick filaments in some smooth muscle partially dissolve and reform during the cycle of contraction and relaxation (Godfraind-De Becker and Gillis, 1988; Watanabe et al, 1993; Xu et al, 1997). Phosphorylation of the $20-\mathrm{kD}$ regulatory myosin light chain (MLC) of smooth muscle is known to cause monomeric myosins in solution to self-assemble into thick filaments (Suzuki et al. 1978, Craig et al, 1983, Trybus et al. 1984). Recently our laboratory has shown that mechanical oscillation applied to resting smooth muscle causes the thick filaments in the muscle to partially dissolve (Kuo et al, 2001). This study explores the role of myosin light chain (MLC) phosphorylation in thick filament reassembly following mechanical perturbation in intact airway smooth muscle, and also examines whether the mechanism that controls thick filament formation in vitro is also operative in vivo. Wortmannin, a cell-permeant inhibitor of myosin light chain kinase (MLCK) (Nakanishi, 1992) is used in our experiments to inhibit the phosphorylation of MLC.

\section{1Mechanism of contraction in smooth muscle}


As illustrated in Fig 1, the intracellular free calcium level $\left(\left[\mathrm{Ca}^{2+}\right]_{i}\right)$ in smooth muscle plays a key role in smooth muscle contraction. The increase of $\left[\mathrm{Ca}^{2+}\right]_{i}$, which is due to either influx of $\mathrm{Ca}^{2+}$ from the extracellular spaces or release of $\mathrm{Ca}^{2+}$ from the intracellular stores (endoplasmic reticulums (ER)) or both (Gunter, 1994 and Himpens, 1995), activates a series of intracellular reactions. The calcium influx across the sarcolemma under physiological conditions occurs through ion channels $\left(\mathrm{Ca}^{2+}\right.$-selective channels or nonselective cation channels, which can be voltage dependent or voltage independent), or via exchangers. Calcium release from intracellular stores is facilitated by inositol 1, 4, 5trisphosphate $\left(\mathrm{IP}_{3}\right)$ - regulated channels or by the mechanism of $\mathrm{Ca}^{2+}$-induced $\mathrm{Ca}^{2+}$ release, generally via ryanodine receptor-regulated channels. Binding of $\mathrm{Ca}^{2+}$ ions with the complex of calmodulin and MLCK leads to phosphorylation of the $20-\mathrm{kDa}$ myosin light chain (MLC). The phosphorylation of MLC consequently results in an increase in myosin ATPase activity and cross-bridge cycling (see Horowitz et al, 1996, for a review). What has been described above is the well-known role of MLC phosphorylation in the contraction of smooth muscle. Another possible role for MLC phosphorylation is in regulating thick filament formation, which is the emphasis of my current research.

\section{2 Lability of smooth muscle myosin filaments}

The lability of myosin thick filaments in smooth muscle has been known for a long time. Myosin thick filaments were initially observed by electron microscopy only in contracted smooth muscle, and relaxed smooth muscle contained only thin filaments, which led to the idea that smooth muscle myosin filaments, unlike that in striated muscle, appear to be present only in the activated state (Kelly and Rice, 1969). Other early experiments also 
supported the conclusion. For example, X-ray diffraction experiments in mammalian smooth muscle (taenia coli of guinea-pig) found that an actin pattern could be observed and it is identical with the actin pattern from other intact muscles, but there were no sign of myosin filament reflexions (orders of 432 A) (Elliott, 1964). However, the initial idea did not have a deep impact on the course of smooth muscle research and subsequent studies soon started to challenge the notion that myosin filaments dissolved totally in relaxed smooth muscle.

Some investigators in the 1970s and early 1980s (e.g., Devine and Somlyo, 1971; Cooke and Fay, 1972; Small and Sobieszek, 1980) found that thick filaments were present in both relaxed and contracted muscle, suggesting that the earlier negative observations were results of limitations of preparative techniques that were employed. The sedimentation velocity experiments by Kendrick-Jones et al (1987) further indicated that in vertebrate smooth muscle myosin, three main species could be identified: polymer (filament), extended monomer (6S) and folded monomer (10S). Moreover, it has been shown in some smooth muscles that assembly of the thick filaments (possibly from the phosphorylated monomeric myosin pool in the cell) occurred during contraction (Godfraind-De Becker 1988, Gillis et al. 1988, Watanabe et al. 1993 and Xu et al. 1997). In vitro studies on vertebrate smooth muscle and non-muscle myosin filament assembly by Suzuki and co-workers (1978) and subsequently by Kendrick-Jones and co-workers (1980, 1981 and 1983) demonstrated that the 20-kD light chain phosphorylation may play a role in regulating thick filament assembly. However, electron microscopy of rapidly frozen vascular smooth muscle in a relaxed state has demonstrated that thick filaments 
were present even though the myosins were not phosphorylated (Somlyo et al. 1981). Our recent observations showed that by imposing length oscillation on airway smooth muscle in the relaxed state, partial dissolution of the thick filaments could be induced (Kuo et al, 2001). The exact role of MLC phosphorylation in the dissolution and reformation of the thick filaments is still unknown.

\section{3 Location of the regulatory light chains on myosin}

Myosin regulatory light chain (MLC) is generally considered to sit at the neck region of the head, possibly extending across the hinge region between the head and tail (S1-S2 junction) portions of the myosin molecule (Ficker et al. 1981; Vibert \& Craig 1982; Kendrick-Jones et al. 1982). Fig. 2 shows a conventional myosin subunit structure. Each myosin head contains a regulatory light chain, where it is specifically phosphorylated by the light-chain kinase (MLCK) (Adelstein \& Klee 1981). There are therefore two regulatory light chains for every myosin. In the gizzard light chain it has been shown that a single serine residue (19 residues from the $\mathrm{N}$ terminus) is phosphorylated (Jakes et al. 1976) by MLCK. The globular heads hydrolyze ATP leading to cross-bridge cycling, while the rod-shaped tail is probably responsible for the formation of thick filaments and for the transmission of force generated under physiological conditions. Studies from rabbit skeletal myosin suggested that these two functions are independent (Onishi et al, 1978). However, the disassembly of myosin thick filaments in smooth muscle is to some extent accompanied by a stoichiometric amount of ATP (3mol of ATP per mol of myosin) and a remarkable depression of Mg-ATPase activity (Onishi et al, 1978), 
indirectly suggesting that myosin light chain phosphorylation regulates cross-bridge cycling and myosin filament formation at the same time.

\section{4 Plasticity of smooth muscle}

In general, smooth muscle has the ability to generate force over a large length range. The phenomenon is called plasticity of smooth muscle. Smooth muscle, like striated muscle, possesses serial arrangement of identical contractile units. Shortening of the muscle depends on length change of every individual unit (Huxley, 1980). Since each unit in series contributes incrementally to the length change of the whole, a change in the number of units in series will directly alter muscle velocity and compliance. The finding of a direct and nearly linear dependence of these two parameters on adapted muscle length is therefore highly suggestive that smooth muscle has the ability to add or subtract contractile units to the serial arrangement of its contractile apparatus (Ford et al, 1994). According to the model of plasticity (Pratusevich et al, 1995), if a single cell preparation of smooth muscle is stretched, there would be more contractile units added in series. On the other hand, if it is shortened, the number of contractile units would be decreased. To allow this structural change, theoretically, there should be a mechanism that regulates thick filament assembly/disassembly. We believe that this mechanism is likely related to phosphorylation of the regulatory myosin light chain in smooth muscle.

\section{5 In vitro studies of myosin}

In vitro experiments are often the first step to identify and characterize in vivo mechanisms. In vitro studies have shown that a myosin thick filament is composed of 
many individual myosin monomers (Trybus et al 1982). Early studies indicated that Myosins existed as a monomer-polymer equilibrium, and that myosin thick filament formation depended on polymerization by a condensation-elongation mechanism (Josephs \& Harrington, 1966, 1968). We now know that the smooth muscle myosin monomer exists in a two state, fold and extended states (Kendrick-Jones et al, 1987). The manifestation of these two states depends on the presence of MgATP, the ionic strength and the state of phosphorylation of the myosin light chain. In solution, myosin filaments consisting of unphosphorylated monomers in low ionic strength $(0.15 \mathrm{M} \mathrm{KCl})$ are depolymerized by MgATP into 10S monomers, which have a folded structure (Suzuki et al. 1978). Their rods (the tail portion) are folded back upon themselves into approximately thirds. These folded, unphosphorylated myosin molecules are not able to form thick filaments. Addition of salt and phosphorylation transform the $10 \mathrm{~S}$ conformation to $6 \mathrm{~S}$ whose tails are extended (Trybus and Lowey, 1987). The transformation described above (also shown in Fig. 3) has been demonstrated in sedimentation equilibrium and calculated from the diffusion and sedimentation coefficients (Trybus et al, 1982, Craig et al, 1983 and Horowitz et al, 1994). The 10S myosin was originally thought to be a dimmer, because its sedimentation coefficient is approximately twice that of skeletal myosin monomer (Suzuki et al. 1978). However, subsequent studies by sedimentation equilibrium and light scattering methods found that both 10S-myosin and 6S-myosin were monomers with a molecular weight of 500,000, only 10-S myosin was greatly different in gross size from 6S-myosin (Suzuki et al., 1982). Analytical ultracentrifugation and electron microscopy further demonstrated that myosins were present in three different conformations of folded $10 \mathrm{~S}$ monomer, extended 
$6 \mathrm{~S}$ monomer and polymerized thick filament simultaneously, and between them there was a dynamic monomer-polymer equilibrium (polymer $\Leftrightarrow 6 \mathrm{~S} \Leftrightarrow 10 \mathrm{~S}$ monomer) (Kendrick-Jones et al. 1987). Under relaxing conditions of smooth muscle $\left(\left[\mathrm{Ca}^{2+}\right]<10^{-8}\right.$ M), light chain dephosphorylation in the presence of MgATP induces myosin filaments to depolymerize into the folded monomers (10S), whereas under contraction conditions $\left(\left[\mathrm{Ca}^{2+}\right]>10^{-6} \mathrm{M}, 1 \mathrm{mM} \mathrm{MgATP}\right)$, phosphorylation promotes the extended state (6S) and leads to filament assembly. The equilibrium is eventually displaced in the direction of the polymer. What are the proportions of myosin monomers and filaments present in smooth muscle in vivo, and how do they change following activation or relaxation are key questions to be answered.

\section{6 In vivo studies of myosin filaments}

From the above in vitro results, we know that MLC phosphorylation can transform monomeric myosin into filamentous myosin. An unanswered question is, does MLC phosphorylation have the same role in vivo? Regrettably, we still do not have an answer. Electron microscopy of rapidly frozen smooth muscle showed that filamentous myosins existed in relaxed state (Somlyo et al. 1981). X-ray diffraction studies in anococcygeus muscle also found that the X-ray diffraction intensity of myosin filaments were obviously strengthened during $\mathrm{K}^{+}$induced contraction, which suggests that the number of myosin filaments may increase during contraction of smooth muscle (Lowy et al, 1970; Poulsen et al, 1987; Watanabe et al, 1993). The assembly of myosin is not observed in all contracting smooth muscles, only in some smooth muscles, for example, in anococcygeus but not in taenia coli (Xu et al, 1997). Recently we have observed that by imposing length 
oscillation on airway smooth muscle in the relaxed state, partial dissolution of the thick filaments could be induced (Kuo et al, 2001). The reduction in number and/or length of the thick filaments (reflected in the decrease of the cross-sectional density of the filaments in electron micrographs) was accompanied by a proportional decrease in isometric force; the density and force values returned to their pre-oscillation level when the muscle was allowed to recover isometrically and subject to periodic electrical stimulation (Kuo et al, 2001). So far the mechanism governing thick filament assembly/disassembly in intact smooth muscle is still poorly understood.

\section{7 Pharmacology of wortmannin and its action on myosin light chain kinase (MLCK)}

Wortmannin is a hydrophobic steroid-related product (Fig. 4) of the fungus Talaromyces wortmanni that can inhibit a series of enzymes in signal-transduction pathways based on its concentration (Table 1). We know that wortmannin has antifungal activity (Brian et al 1957), hemorrhage activity (Abbas 1988), anti-in-flammatory activities (Wiesinger et al 1974), and the ability to inhibit respiratory burst of neutrophils, monocytes, and macrophages (Baggiolini et al. 1987). Here, I only introduce its inhibitory properties for MLCK.

Wortmannin is a relatively selective inhibitor for MLCK (Nakanishi et al. 1992). In general, every MLCK molecule has three different functional regions: a catalytic domain, an inhibitory domain, and a calmodulin-binding domain (Guerrieto et al 1986 and Ikebe et al. 1987). Wortmannin interacts directly with the catalytic domain leading to inhibition of MLCK activity. The other two domains can be removed by limited tryptic digestion, 
but the remaining fragment including catalytic domain still retains the full enzyme activity, only that it is no longer camodulin-dependent. The inhibition of MLCK by wortmannin can be prevented by a high concentration of ATP, and the inhibitory action of wortmannin is interrupted by preincubation of ATP with MLCK. The results strongly suggest that wortmannin binds at or close to the ATP binding site of the enzyme. In vitro experiments suggested that the inhibition of wortmannin was irreversible (Nakanishi et al. 1992). This was explained by covalent reactions between wortmannin and MLCK molecules. Wortmannin has at least two sites at which the compound could form covalent bonds with MLCK. One is the lactone ring which would be attacked by an amino group of the protein to form an amide bond, and the other is $\alpha, \beta$-unsaturated ketone which would be attacked by a thiol group of a cysteine residue to form a 1, 4-adduct (Nakanishi et al. 1992). It has been shown in in vivo experiments that wortmannin (1 $\mathrm{MM})$ completely suppressed the high- $\mathrm{K}^{+}$-induced contractions (Takayama et al. 1994; Burdyga et al. 1998). The diminishment of force induced by wortmannin was accompanied with little or no change in $\left[\mathrm{Ca}^{2+}\right]_{i}$ and electrical activity (Burke et al. 1996 and Burdyga et al. 1998). Burke and his colleagues showed that the action of wortmannin in canine gastric smooth muscles was irreversible, same as the original report from in vitro experiments (Nakanishi et al. 1992). They also indicated that in some other tissue types, such as canine and guinea pig ileum, canine and guinea pig colon, and human colon, spontaneous contractions in the presence of wortmannin were reduced or even abolished, but immediately there would be a partial recovery (from 19-41\%) of phasic contractile activity after washout of wortmannin. In summary, because of its selective action on 
MLCK, wortmannin can be a useful tool to explore the role of MLC phosphorylation in the formation of myosin filament.

My thesis research was undertaken to examine the role of MLC phosphorylation in thick filament reassembly following mechanical perturbation in intact airway smooth muscle, and to determine whether the mechanism that controls thick filament formation in vitro is also operative in vivo. Our working hypothesis is that MLC phosphorylation is a prerequisite for thick filament formation in vivo. An important issue to be addressed is whether the dynamic nature of the contractile filaments in smooth muscle could result in a mechanism of contraction that is fundamentally different from that of striated muscle. If the contraction/relaxation cycles in smooth muscle involves assembly/disassembly of the thick filaments, and if phosphorylation of MLC plays a key role in the filamentogenesis, then we have to reevaluate the current theories of smooth muscle contraction that do not take into account the evanescence of myosin filaments. 


\section{Materials and Methods:}

\section{1 Muscle preparation.}

Swine tracheal smooth muscle from a local abattoir was used in the experiments. The tracheas were kept in ice-cold physiological saline immediately after their removal from the animals. 5-6 thin trips of smooth muscle bundles (approximately $6 \times 1.5 \times 0.2 \mathrm{~mm}$ in dimension) were dissected from each porcine trachea, with the epithelial layer and the connective tissue of the adventitia carefully removed. Aluminum foil clips were attached to both ends of every muscle strip. The clipped muscle trip was then placed in a muscle bath; one end of the muscle was connected to a stationary hook inside the muscle bath, the other end was connected to a servo-controlled force/length lever. In the waterjacketed muscle bath, physiological saline solution (PSS) with $\mathrm{pH} 7.4$ at $37^{\circ} \mathrm{C}$ was bubbled with a gas mixture $\left(5 \% \mathrm{CO}_{2}-95 \% \mathrm{O}_{2}\right)$, with a composition (in $\mathrm{mM}$ ) of $118 \mathrm{NaCl}$, $5 \mathrm{KCl}, 1.2 \mathrm{NaH}_{2} \mathrm{PO}_{4}, 22.5 \mathrm{NaHCO}_{3}, 2 \mathrm{MgSO}_{4}, 2 \mathrm{CaCl}_{2}$ and $2 \mathrm{~g} /$ liter dextrose. The muscle preparation was equilibrated in the bath for $\sim 1 \mathrm{~h}$ to obtain a maximal, stable isometric force. During the period of equilibration, the muscle was activated by electric field stimulation (EFS) once every $5 \mathrm{~min}$ to produce sustained tetani with sinusoidal alternating currents at $60 \mathrm{~Hz}$ for $12 \mathrm{~s}$. Also during the period, a reference length (close to the in situ length) for the muscle $\left(\mathrm{L}_{\mathrm{ref}}\right)$ was determined for each preparation. At $\mathrm{L}_{\mathrm{ref}}$, the passive tension of the preparation was about $1-2 \%$ of maximal isometric force $\left(\mathrm{F}_{\max }\right)$.

\section{2 Apparatus.}


Muscle force was measured with a photoelectric type of force transducer with a resonant frequency of $1 \mathrm{kHz}$ and a signal-to-noise ratio of $>50$. The length oscillation was applied through a servomotor. Displacement of the servomotor coil was driven by a signal generated from a function generator that controlled both the amplitude and frequency of the oscillation. The highest frequency that the motor could follow was $\sim 1 \mathrm{kHz}$. Details of the apparatus have been described by us (Wang et al, 2000; Kuo et al, 2001; Qi et al, 2002).

\section{3 Wortmannin preparation}

Wortmannin, a cell-permeant inhibitor of myosin light chain kinase (MLCK) (Nakanishi et al., 1992), was used in the experiments to inhibit MLC phosphorylation. Wortmannin is extremely unstable and has a half-life of only a few minutes in aqueous solutions. Hence, in our experiment, wortmannin was pre-dissolved in sterile DMSO (Dimethyl Sulfoxide) from Sigma as $1-\mathrm{mM}$ stock solution. The stock concentration was 1000 -fold the final concentration used to treat cells and the stock solution was stored in aliquots at $-20^{\circ} \mathrm{C}$. Wortmannin was thawed immediately before use and mixed with PSS in 1:999 volume ratio to obtain the final concentration of $1 \mu \mathrm{M}$ for the experiments. For control experiments (without wortmannin) used to investigate the effects of DMSO alone on isometric force and thick filament density, the volume of DMSO added to the bath was equal to the amount used as vehicle for wortmannin in actual experiments.

\section{4 Experimental Procedure}


Four tracheas were used for the study. Five muscle trips were dissected from each trachea. After equilibration in the muscle bath, each of the five trips was fixed in one of the 5 time points during the course of the experiment, as illustrated in Fig 5. Data at each time point represented results averaged for five strips from four different animals. The total number of muscle trips fixed for EM examination was therefore 20. At Time 1, after the equilibration, the sample was fixed for later EM examination. This was used as the control. At Time 2, after the equilibration, $1 \mu \mathrm{M}$ wortmannin was put into the muscle bath. After about $45 \mathrm{~min}$, the isometric force diminished to nearly zero. At Time 3, after administration of wortmannin, mechanical oscillation was used to disrupt the thick filaments and to induce filament dissolution. The amplitude of the sinusoidal length oscillation used was $60 \%$ of $L_{\text {ref }}$ (peak to peak). The oscillation therefore caused a $30 \%$ $L_{\text {ref }}$ stretch of the muscle. The amount of stretch was about the same as the stretch experienced by the smooth muscle in the airways during a deep inspiration. The maximal passive force measured during oscillation was about one-quarter of maximal isometric force. The frequency of the oscillation was $0.5 \mathrm{~Hz}$. This frequency is close to the respiration rate of pigs. Time 3 would allow us to determine the extent of thick filament disassembly due to mechanical disruption in the absence of MLC phosphorylation. At Time 4, after the oscillation (same as the above), the muscle was allowed to recover in the presence of wortmannin. This would allow us to determine whether reassembly of thick filaments was possible without MLC phosphorylation. At time 5, after the oscillation, the muscle was allowed to recover in the absence of wortmannin. Our preliminary results indicated that the effect of wortmannin in intact smooth muscles was partially reversible, that is, after washing out of wortmannin, force recovered partially. 
This last experiment would therefore be useful for determining if there was any significant irreversible change in the muscle preparation after the experimental protocol.

\section{5 Electron microscopy}

The fixing solution contained $1.5 \%$ glutaraldehyde, $1.5 \%$ paraformaldehyde and $2 \%$ tannic acid in $0.1 \mathrm{M}$ sodium cacodylate buffer that was pre-warmed to the same temperature as the bathing solution $\left(37^{\circ}\right)$ before every fixation. At each time point in Fig 5 , the muscle was fixed while in the relaxed state and still attached to the apparatus for 15 min. The replacement of physiological saline with fixing solution occurred in $<1 \mathrm{~s}$. Slightly shaking the fixing container was necessary to remove the layer of water molecules surrounding the muscle tissue during the initial fixation, so that fixing solution can enter the tissue more quickly. Care was taken not to disrupt the muscle mechanically. After the initial fixing $(15 \mathrm{~min})$, the sample was removed from the apparatus, cut into small blocks, approximately $1 \times 0.5 \times 0.2 \mathrm{~mm}$ in dimension, and placed in the same fixing solution for $2 \mathrm{~h}$ at $4^{\circ} \mathrm{C}$ on a shaker. This was followed by three 10 -min washes in $0.1 \mathrm{M}$ sodium cacodylate buffer. The tissue was then fixed with $1 \% \mathrm{OsO}_{4}$ in $0.1 \mathrm{M}$ sodium cacodylate buffer for $2 \mathrm{~h}$ as the secondary fixation, followed by three washes with distilled water (30min). Next, the blocks were further treated with $1 \%$ uranyl acetate for 1 hour (en bloc staining) still followed by washes with distilled water. Increasing concentrations of ethanol $(50 \%, 70 \%, 80 \%, 90 \%$ and $95 \%)$ were used (ten minutes each) in the process of dehydration. $100 \%$ ethanol was used for the final process of dehydration; the final dehydration includes three-time washes and each time lasted 10min. Then, propylene oxide (three 15-min washes for each) was followed. Upon finishing 
the above procedure, the specimen was ready for embedding in resin (TAAB $812 \mathrm{mix}$, medium hardness). The blocks were first soaked in the mixing solution of resin and propylene oxide with a ratio of $1: 2$ and shook for $30 \mathrm{~min}$. After this step, the mixing solution of resin and propylene oxide with a ratio of 2:1 was used to soak the blocks and shook for $30 \mathrm{~min}$. Finally, the specimen was put in the pure resin and left overnight before it was embedded in molds. Next day, the specimen was placed in an oven at $60^{\circ} \mathrm{C}$ for $8 \mathrm{~h}$. The embedded blocks were sectioned on a microtome using a diamond knife. The thickness of the sections were 90 150 nm (silver-gold color). The sections were then placed on 400-mesh copper grids, stained with $1 \%$ uranyl acetate and Reynolds lead citrate for 4 and 3 min respectively. A Phillips 300 electron microscope was used for obtaining the images of the cross-sections of the muscle cells.

\section{6 Morphometric analysis}

Fifteen pictures were taken for each muscle sample fixed, for a total of 300 pictures. All pictures contain one whole cell cross-section. Among the 15 pictures from each sample, 5 contained nuclei, 5 contained central cluster of mitochondria, and 5 contained scatter mitochondria and other organelles. The locations of these three sections are shown in Fig 6. This sampling choice ensured that the central, near-central, and end segments of muscle cells were all included in the examination. Before our analysis, we checked the statistical differences among these three segments in terms of thick filament density (Fig 6). No statistically significant difference was found among the segments. Therefore, results were grouped together in the final analysis. Sampling and analysis were carried out in a "blind" manner to avoid possible bias. This is because myosin thick filaments 
(with a diameter of 15-20 nm) were identified by eye and manually counted for the whole cell cross-section. The codes were revealed only after all samples had been analyzed. The cell cross-sectional area was measured using a morphometric digital device made by Carl Zeiss of Germany. The thick filament density was obtained by dividing the number of thick filaments counted for the whole cell cross-section by the area of the cell crosssection minus area occupied by nuclei, mitochondria and other organelles. The thick filament density measured was therefore the cytoplasmic density. 


\section{Results:}

Fig.7 show two samples of electron micrographs of cross-sections of smooth muscle cells from our experiments. Fig. 7-A was fixed under the control condition, namely, Time 1 in the protocol of the experiment (as shown in Fig.5), while the Fig. 7-B was a test condition (Time 4 ) where the segments were exposed in wortmannin $(1 \mu \mathrm{M})$ for $\sim 45 \mathrm{~min}$ and they were fixed after a period of 30 min post oscillation. During this period, muscles were allowed to "recover" in the absence of further mechanical perturbation, but in the presence of wortmannin. The muscles were also stimulated electrically once every $5 \mathrm{~min}$ to monitor force recovery. These pictures show two complete smooth muscle cells with nucleus and organelles, and arrows indicate myosin thick filaments, surrounded by actin thin filaments.

\section{1Effects of wortmannin on the generation of isometric force}

The results of the experiments are summerized in Fig 8. The control group (Time 1) has an average tetanic isometric force (after 1 hour equilibration) of $171 \pm 14 \mathrm{kPa}$. In the presence of $1 \mu \mathrm{M}$ wortmannin (Time 2 ) for a period of $\sim 45 \mathrm{~min}$, the electrically elicited isometric force was reduced to virtually zero (Fig 8). At Time 3, the muscles had been subjected to a 5-min period of length oscillation, with a frequency of $0.5 \mathrm{~Hz}$ and a stretch-amplitude of $30 \%$ of reference length of the muscle $\left(\mathrm{L}_{\text {ref }}\right)$ in the presence of wortmannin. At Time 4, muscle preparations were allowed to "recover" in the absence of further mechanical perturbation, but in the presence of wortmannin, the force was not recovered. In the last group (Time 5), with wortmannin removed, the isometric force recovered partially (71\%). Full recovery of the force was not attained after incubation of 
the muscle in zero-wortamnnin PSS for $50 \mathrm{~min}$ with repeat washes and electrical stimulation (Fig.8 Time 5). One-way ANOVA showed that the variation in force was significant $(\mathrm{P}<0.05)$.

\section{2 Thick filament density in different cell segments}

Total density assessed from the 3 different cell segments that include nuclei, mitochondria aggregation and scattered organelles, as mentioned in the section of Materials and Methods. This was done to ensure even sampling of filaments in all cell locations. We need to know whether the density values of thick filaments from these three segments under the same condition were different or not before we can pool them together in the final analysis. The results of myosin densities in the three cellular sections from the four control muscle preparations showed that no statistical difference among the different cell segments existed $(\mathrm{P}>0.05$, one-way ANOVA). The results were therefore pooled. The densities measured from 15 cell cross-sections in each muscle sample were first average; the mean of this average was then averaged with the means from 3 other muscle samples fixed under the same experimental condition.

\section{3 Effects of wortmannin on cross-sectional density of myosin thick filament}

The density of thick filaments in the control group was 65 (filaments) $/ \mu \mathrm{m}^{2}$. The density was reduced slightly $(9 \%)$ to $59 / \mu \mathrm{m}^{2}$ in the presence of wortmannin before mechanical agitation (Fig. 8, Time 2). According to statistical analysis (pair t-test), this reduction was not significant. After the imposed length oscillation, the density decreased significantly to $75 \%\left(49 / \mu \mathrm{m}^{2}\right)$ of the control value. At Time 4 , following oscillation and 
"recovery" in the presence of wortmannin, the density decreased further to $46 / \mu \mathrm{m}^{2}$. However, the density difference between Time 3 and 4 was not significant (t-test)(Fig. 8). Results from Time 3 and 4 suggest that no recovery of thick filament density occurred with wortmannin present in the solution, despite repeated stimulation in isometric state (Fig. 8). The thick filament density recovered fully after the removal of wortmannin (Fig. 8, Time 5). One-way ANOVA showed that the variation in the density associated with the 5 experimental conditions was significant $(P<0.05)$. The density variation among Time 1, 2 and 5, however, was not significant and neither was the density difference between Time 3 and 4 (Fig. 8). Table 2 lists the averaged number of thick filaments per cell cross-section and averaged cross-sectional area of the cells examined in this study.

\section{4 Control observations}

Because DMSO was used as a solvent to dissolve wortmannin in our experiment, we could not exclude the effect of DMSO alone on isometric force and thick filament density. We therefore investigated its effects as part of the control observation. $10 \mu \mathrm{L}$ of DMSO (the same amount used as vehicle for wortmannin in actual experiments) was added to the $10 \mathrm{~mL}$ muscle bath for $30 \mathrm{~min}$, no change in activate isometric force or resting tension could be detected in the pair of muscle preparations tested. The thick filament density was not changed either (t-test, $\mathrm{P}>0.05$ ); for the control preparation, the density was $65.8 \pm 5.2$ filaments $/ \mu \mathrm{m}^{2}$, for the test $(1 \mu \mathrm{L} / \mathrm{mL}$ DMSO), the density was 63.2 \pm 2.9 filaments $/ \mu \mathrm{m}^{2}$. Eight cell cross-sections for each preparation were used to determine the thick filament density. 


\section{Discussion:}

The major finding of this thesis is that MLC phosphorylation played a key role in myosin thick filament reassembly after partial dissolution induced by oscillatory strains in intact airway smooth muscle. An important implication of this finding is that besides the commonly believed role of MLC phosphorylation in activating myosin ATPase activity, the phosphorylation has another important role during the activation of smooth muscle, and that is formation of the thick filaments.

\section{1 Effects of wortmannin on intracellular $\mathrm{Ca}^{2+}$ transients}

Calcium handing in intact airway smooth muscle appears to be unaffected by wortmannin (Burdyga et al, 1998 and Qi et al, 2002). The change in the myosin thick filament density observed in the presence of wortmannin therefore is not likely due to calcium dependent regulatory pathways upstream of MLC phosphorylation. A recent study from our laboratory showed that calcium played an important role in the maintenance of integrity of the thick filaments in the trachealis muscle (Herrera et al. 2002). The influence of calcium on thick filament formation probably goes beyond the participation of calcium in the $\mathrm{Ca}^{2+}$-calmodulin-MLCK activation pathway that controls MLC phosphorylation; the resting level of intracellular calcium in unphosphorylated trachealis muscle appeared to be important also for the maintenance of thick filaments (Herrera et al. 2002), because by lowering the resting calcium concentration through incubation of muscle in zero external calcium plus EGTA the cross-sectional density of the thick filaments was reduced by $35 \%$. Since there is no evidence that wortmannin altered the resting calcium or MLC 
phosphorylation levels, the change in thick filament density observed in this study is not likely related to changes in resting calcium level.

\section{2 Effect of $M L C$ phosphorylation on isometric force generation}

It is well established that calcium dependent phosphorylation of MLC initiates smooth muscle contraction (Kamm and Stull, 1985). We found that wortmannin's ability to inhibit isometric force production is through inhibition of the MLC phosphorylation (Qi et al, 2002). This is consistent with the established model of smooth muscle activation. Incubation of trachealis muscle in PSS containing $1 \mu \mathrm{M}$ wortmannin resulted in reduction of isometric force to nearly zero over a period of about $45 \mathrm{~min}$ (Fig. 8, Times 2, 3, and 4). Quick freezing of canine trachealis after incubation of the tissue with $1 \mu \mathrm{M}$ wortmannin for the same period of time showed that the level of MLC phosphorylation in maximally stimulated trachealis was reduced to the basal level (Qi et al, 2002). It appears the isometric force generation in airway smooth muscle is totally dependent on MLC phosphorylation.

\section{3 Reversibilty of wortmannin inhibition}

Nakanishi et al.'s (1993) original report indicated that wortmannin binding to MLCK was irreversible. But Burke et al (1996) mentioned that in canine and guinea pig ileum, canine and guinea pig colon; and human colon showed a reversible effect of wortmannin (a recovery of phasic contractile activity from 19 to $41 \%$ ). Our results showed that the isometric force inhibited by wortmannin could be reversed to $\sim 71 \%$ of original tetanic isometric force in the control group. However, a complete recovery was not achieved. 
Burke et al (1996) explained the difference in force recovery as due to differences in muscle preparations and argued that the drug might not have completely permeated the muscle under conditions of partial reversibility. This however did not explain why the force was inhibited in the first place. It is not entirely clear why there is discrepancy among findings regarding reversibility of wortmannin inhibition, our own findings suggest that force inhibited by wortmannin is at least partially reversible and the thick filament density change associated with wortmannin inhibition is completely reversible.

\section{4 The relationship between MLC phosphorylation and formation of myosin thick}

\section{filament}

The Formation of myosin thick filaments appears to be partially dependent on MLC phosphorylation (Fig. 8). We observed that at least some of the myosin thick filaments are present in resting muscle (Fig. 8). In the relaxed state MLC phosphorylation in trachealis muscle was virtually zero (Qi et al, 2002); after the addition of wortmannin $(1 \mu \mathrm{M})$, the level of phosphorylation was not changed (Qi et al, 2002). Kendrick-Jones et al (1987) have demonstrated that polymerization of thick filaments could happen in unphosphorylated myosins when the myosin concentration reached a critical level. This probably explains why there are thick filaments present in the relaxed muscle. KendrickJones et al (1987) also showed that MLC phosphorylation favors formation of thick filaments from monomeric myosins. Although the present study did not examine the thick filament density in activated muscle (where the light chains are phosphorylated), a recent study from our laboratory did observe a large increase in thick filament density after the muscle was activated (Herrera et al, 2002). 
Since the level of MLC phosphorylation in the resting trachealis was near zero, it is not surprising to see that addition of wortmannin did not induce a further decrease in the cross-sectional density of the thick filaments in the relaxed muscle (Fig. 8, Time 2), although the isometric force was abolished. The thick filaments were unstable; a significant reduction in the cross-sectional density of the thick filaments was observed after the muscle was subjected to a brief period of length oscillation (Peak-to-peak amplitude $60 \%$ muscle length for $5 \mathrm{~min}$ )(Fig.8, Time 3). The same oscillation protocol was used in one of the recent studies from our laboratory (Kuo et al. 2001) that showed a similar degree of reduction in myosin thick filament density in muscles subjected to the oscillation in the relaxed state without wortmannin. The thick filament lability therefore was not due to the presence of wortmannin but likely due to the fact that the level of MLC phosphorylation was low at resting state. We did not examine the thick filament stability in activated state, it is therefore not known whether the same oscillatory strains applied to activated trachealis would produce the same degree of thick filament disassembly as that observed in the relaxed state. In muscles not exposed to wortmannin, the reduction in thick filament density was transient; the density recovered fully after a few cycles of contraction and relaxation in isometric mode (Kuo et al. 2001). The present results showed that in the presence of wortmannin, the density did not recover even after repeated stimulation in isometric state (Fig, 8, Time 4). It appears that cyclic phosphorylation of MLC is needed for the assembly of thick filaments after they have been partially disassembled by mechanical agitation. Although the force did not recover fully after removal of the inhibitor, the thick filament density recovered to the preoscillation level (Fig. 8, Time5). The incomplete force recovery could be explained by an 
incomplete removal of wortmannin from the intracellular space, with some MLCK still inhibited by the residual wortmannin. The complete recovery of the thick filament density may indicate that thick filament formation does not depend on activation of all available MLCK.

\section{5 Wortmannin selectivity to $M L C K$}

Although wortmannin is a potent MLCK inhibitor, it is not specific. Wortmannin has been shown to inhibit phosphatidylinositol (PI) 3-kinase- $\gamma$, mitogen-activated protein (MAP) kianse (Yamboliev et al, 2000) and protein kinase C. Besides the calciumcalmodulin-MLCK pathway mentioned earlier, MAP kinase may phosphorylate and activate MLCK (Klemke et al. 1997). PKC can directly phosphorylate MLC and also phosphorylate and activate the MAP kinase (see review by Abdel-Latif, 2001). Since the final results of the above mentioned MAP kinase and PKC pathways are phosphorylation of MLC, for the purpose of our study the effects of wortmannin on these pathways need not to be differentiated. Except for MLCK, PKC and MAP kinase, most identified wortmannin targets are PI-3-kinase homologues. These enzymes and MLCK have been listed in Table 1. PI-3-kinases are activated by a high proportion of cell surface receptors, especially those linked to tyrosine kinases, and influence a variety of cellular functions and events. However, these events as far as we know have no acute effects on smooth muscle contraction (see review by Stein, 2001). Therefore, interpretation of the present results can be based only on the observable effects of wortmannin on MLC phosphorylation. 


\section{6 Summary}

The major finding of this thesis research was that myosin light chain (MLC) phosphorylation was required for thick filament formation in intact airway smooth muscle after the thick filaments have been partially disassembled by mechanical strains in the resting, unphosphorylated state. Wortmannin $(1 \mu \mathrm{M})$ completely inhibited isometric force production in trachealis muscle and this force inhibition can be explained by wortmannin's inhibition of MLC phosphorylation. In the presence of wortmannin and after mechanical perturbation, the abolished isometric force and reduced myosin filament density were not recovered even after repeated stimulation; partial recovery of isometric force and full recovery of myosin filament density were observed after removal of wortmannin from the bathing solution. It is concluded that MLC phosphorylation, besides playing an essential role in activating actomyosin ATPase activity, plays an important role in the myosin thick filament formation during muscle activation. This latter role of MLC phosphorylation may be crucial in regulating and facilitating plastic adaptation of smooth muscle to different cell lengths. 


\section{Extra-cellular space}

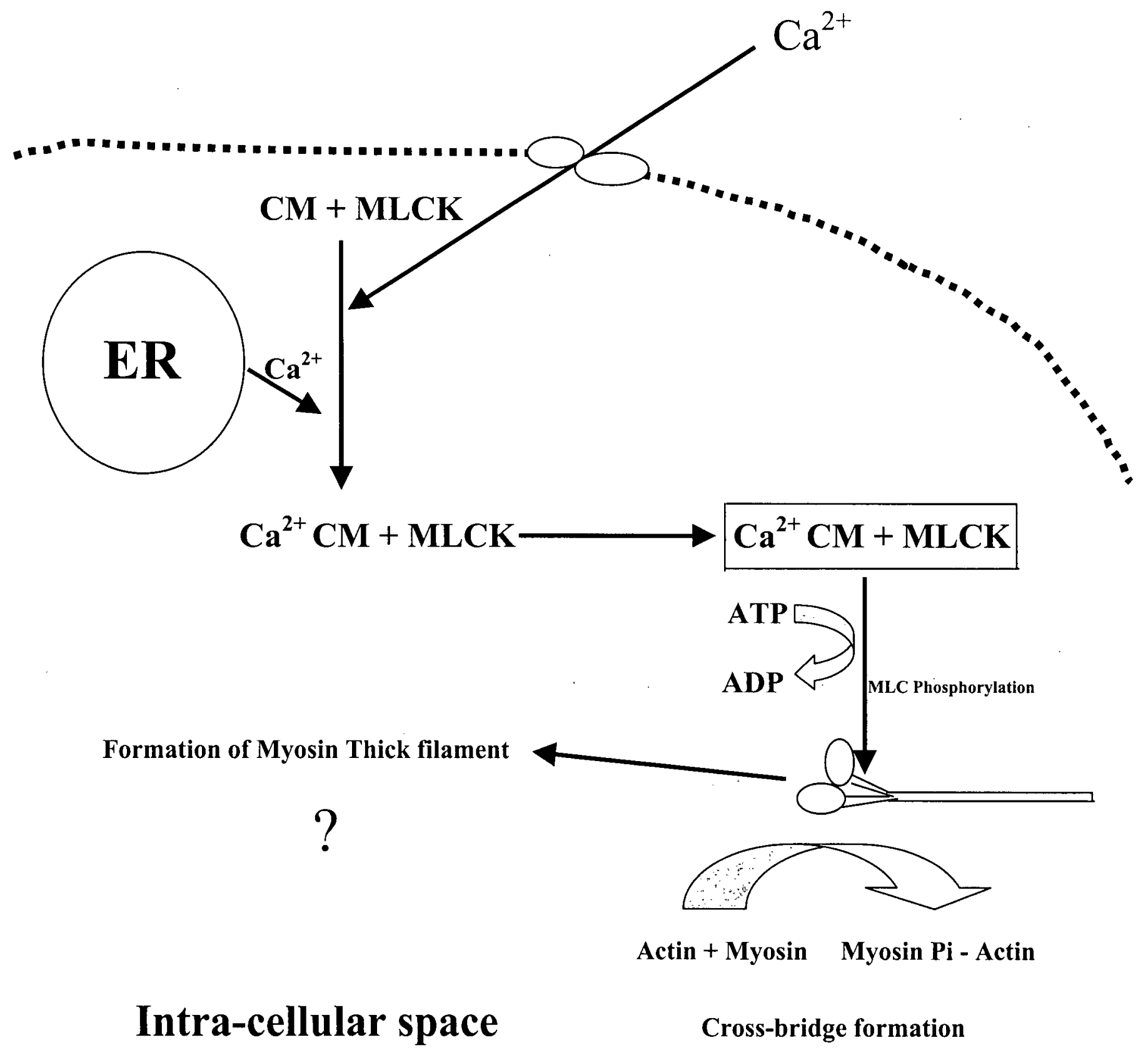

Fig 1. Mechanism of smooth muscle activation. ER, endoplasmic reticulum; CM, calmodulin. 


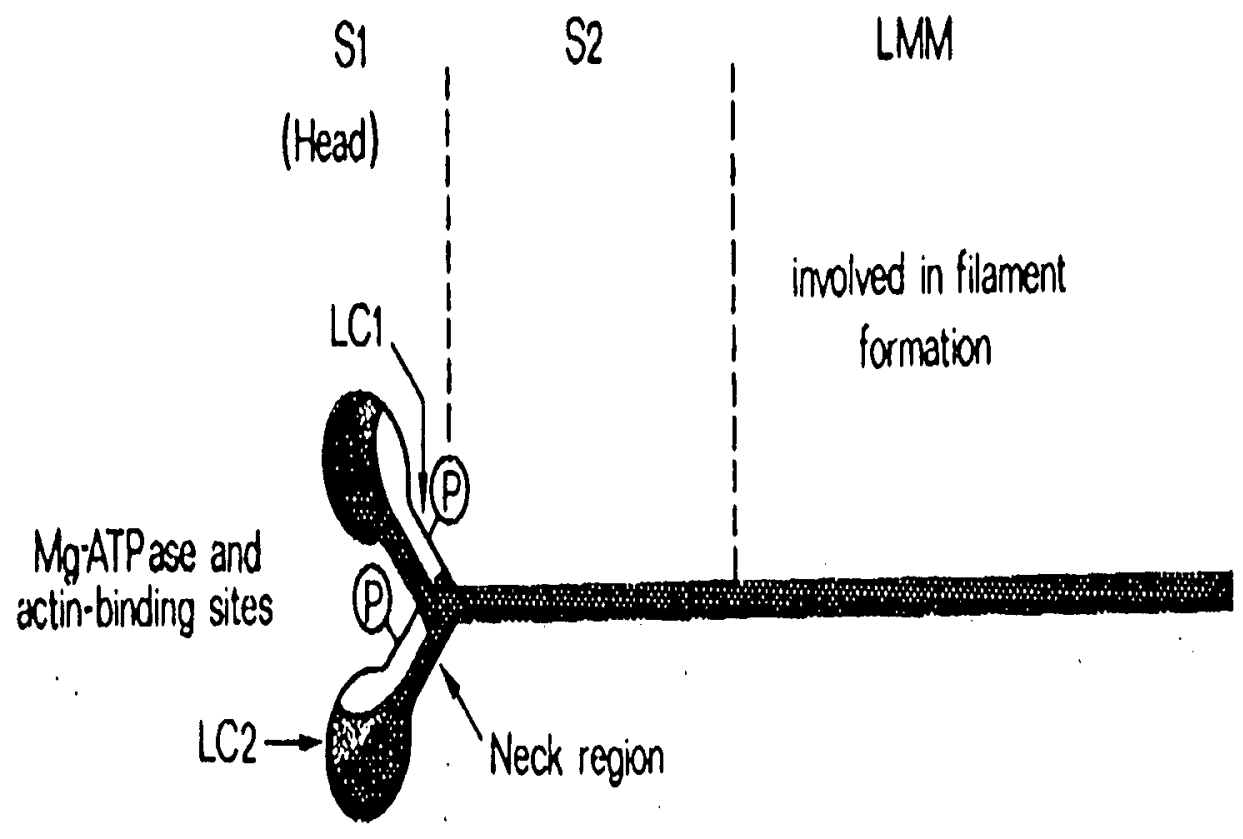

Fig 2. Diagrammatic representation of a myosin molecule illustrating the distribution of functional properties. Myosin is an asymmetric molecule consisting of two heavy chains $(200 \mathrm{kD})$ and two pairs of light chains of two types. The C-terminal halves of the heavy chains form the $\alpha$-helical coiled-coil tail region (LMM and S2) and the $\mathrm{N}$-terminal halves form the globular heads (S1). Each S1 contains one of each type of light chain, called regulatory (LC1, labeled with an encircled P: phosphorylatable) and essential (LC2) light chains. 
A.


$10 \mathrm{~S}$
B.
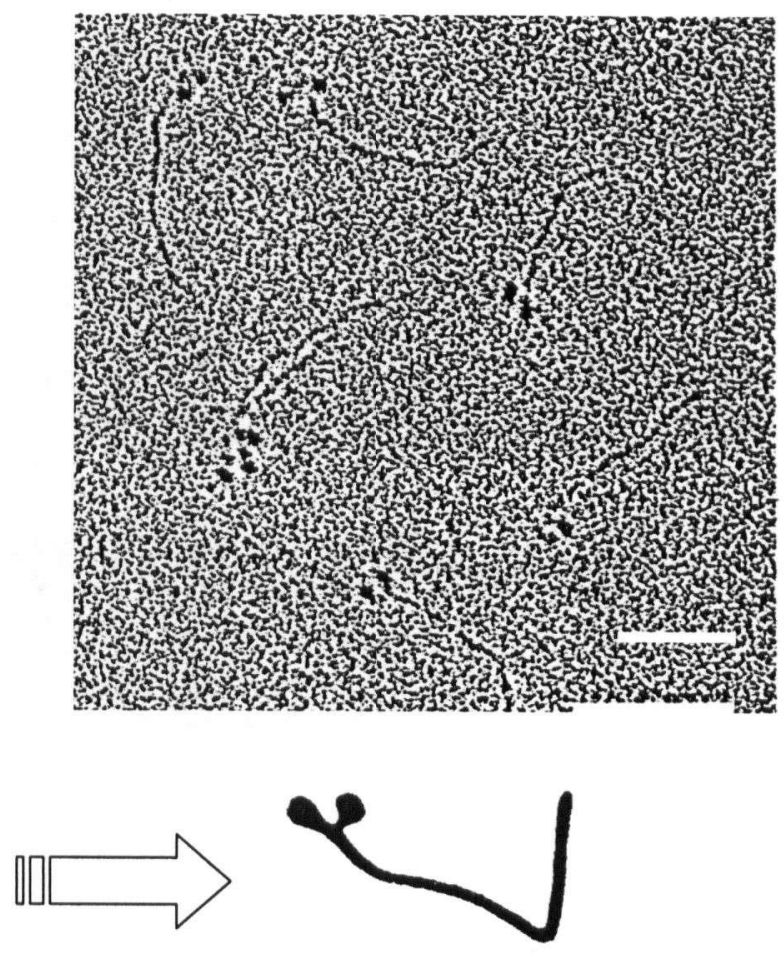

$6 S$

Fig 3. Electron microscopy of rotary-shadowed $10 \mathrm{~S}$ and $6 \mathrm{~S}$ myosin. A. 10S species were formed after addition of MgATP to dephosphorylated minifilaments; the monomers folded back upon themselves into approximately thirds. B. Phosphorylated minifilaments formed $6 \mathrm{~S}$ monomers in the presence of $\mathrm{MgATP}$. The phosphorylated monomers were extended. The white bars in the above electron micrographs represent $0.1 \mu \mathrm{m}$. (Smith et al. review, 1983) 
Fig. 4 Chemical structure of wortmannin and its mechanism of action on MLCK

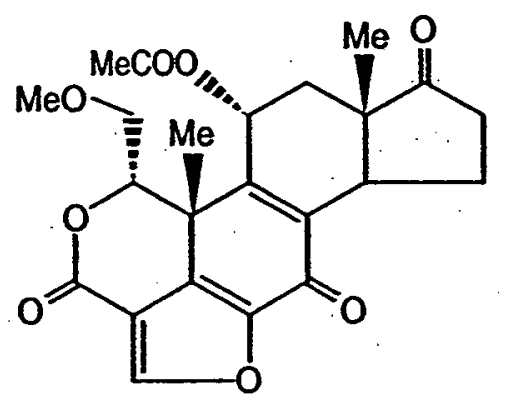

Wortmannin

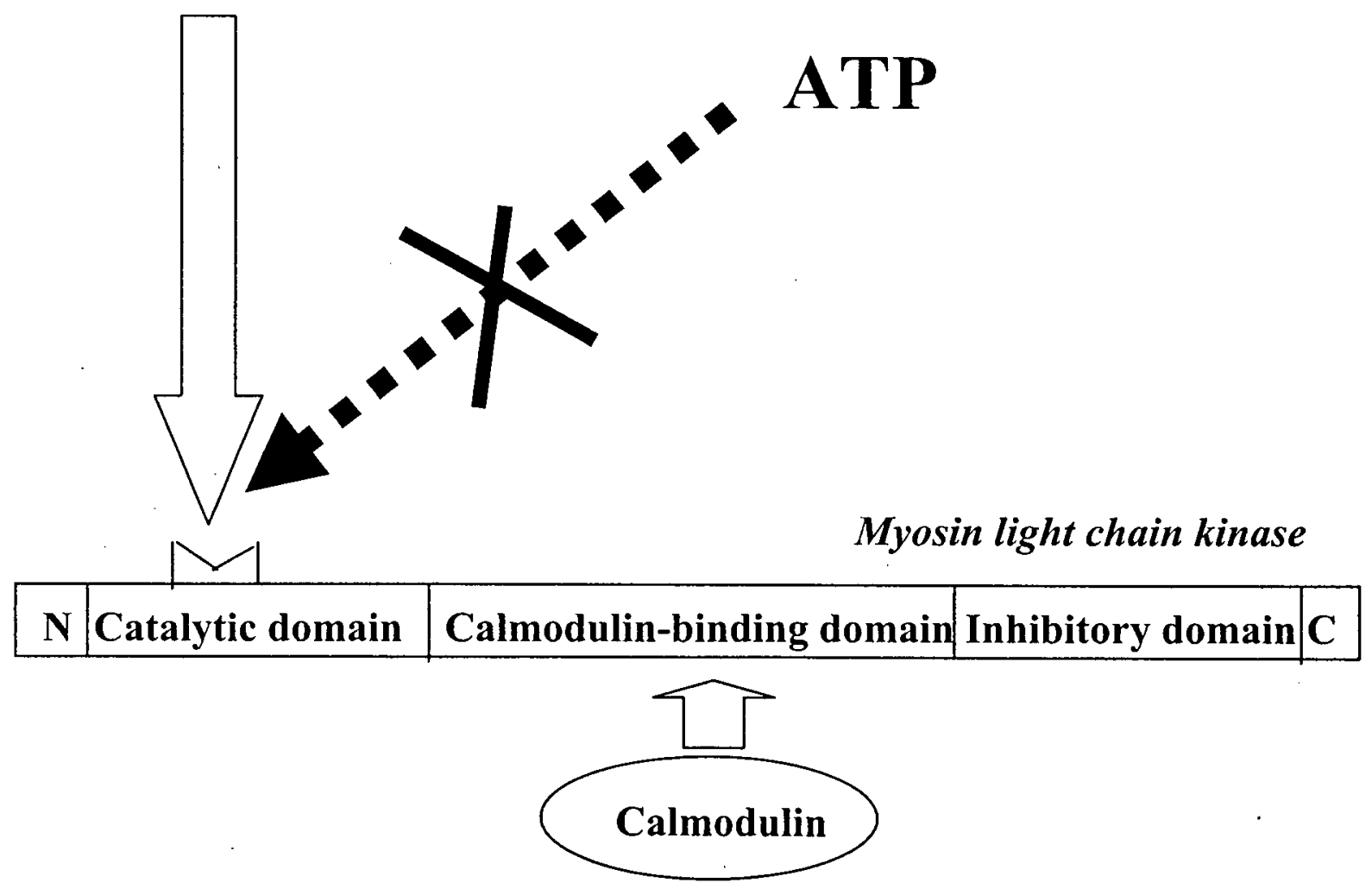




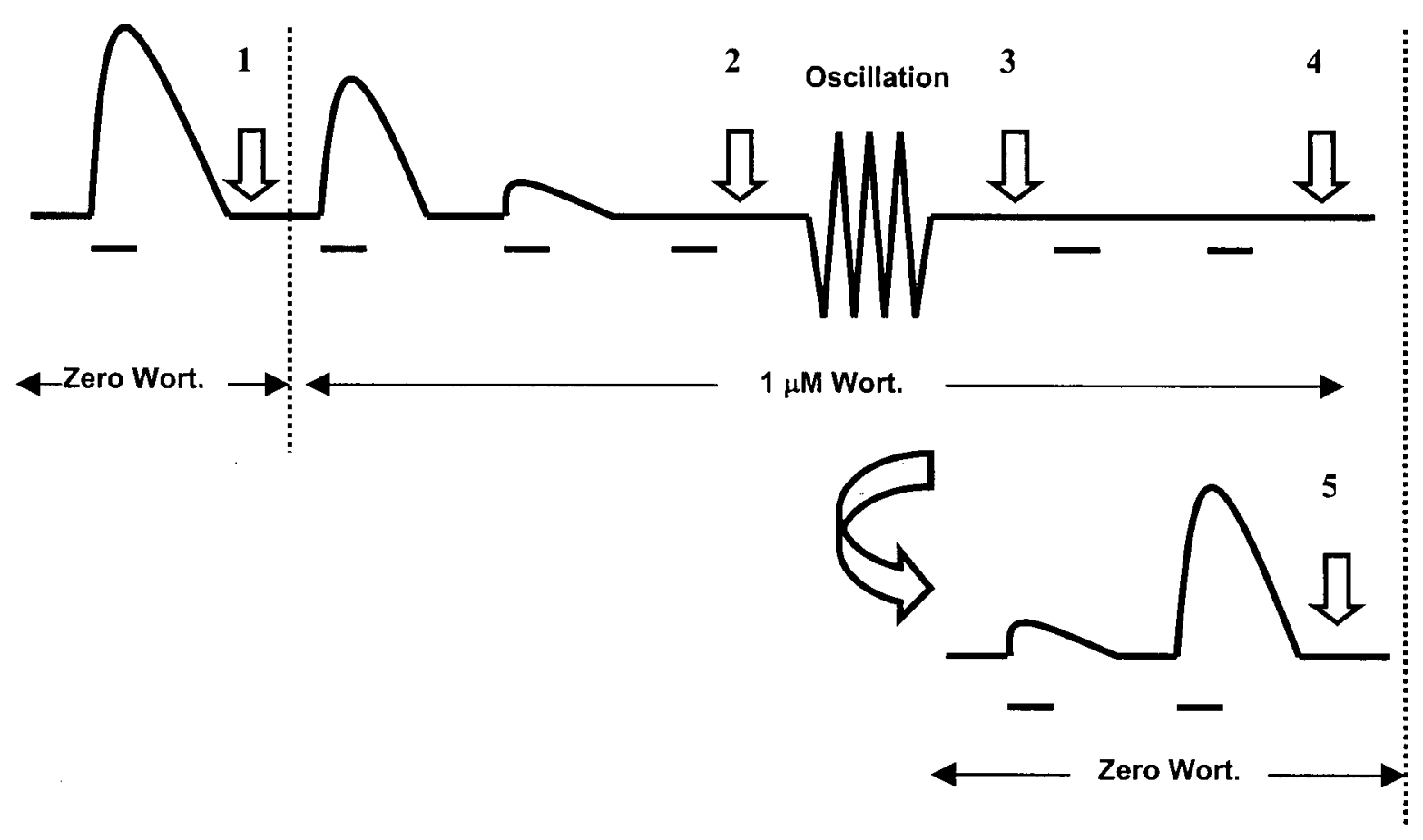

Fig. 5 Schematic drawing illustrating time points during the course of experiment when the muscle samples were fixed for EM examination. The traces indicate force changes. The horizontal bars below the traces indicate electric field stimulation (EFS). All samples were fixed in the relaxed state. Between Time 1 and 2 there were five 12-s stimulations separated by 5-min intervals (note that not all stimulations were illustrated). Between Time 2 and 3, there was a 5- min period of oscillation. Between Time 3 and 4 , there were 5 stimulations over a period of $25 \mathrm{~min}$. Between Time 4 and 5, there were 10 stimulations over a period of $50 \mathrm{~min}$. 


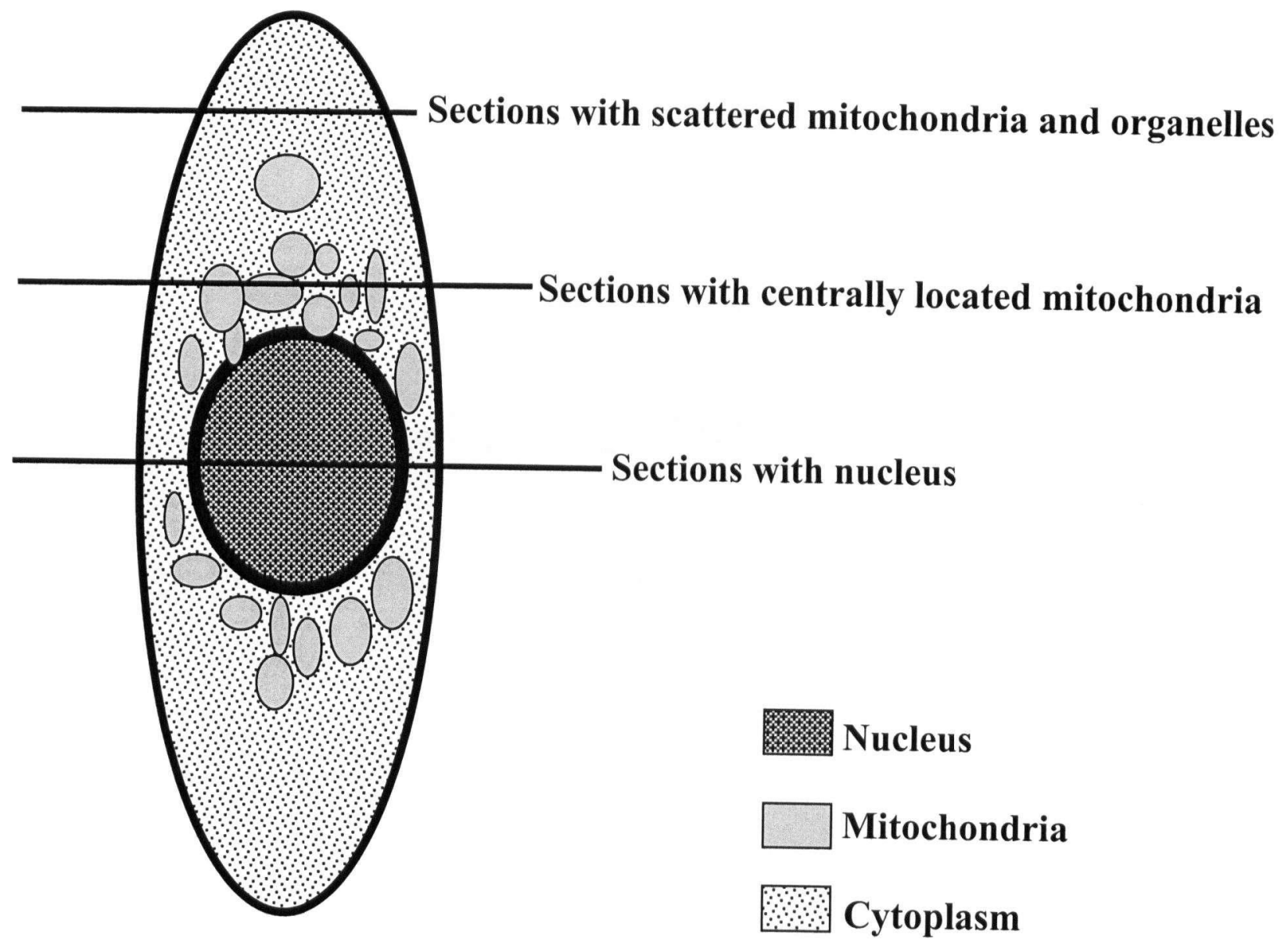

Fig 6 Schematic illustration that shows the three different locations (section planes) that were chosen for electron microscopic examination. 


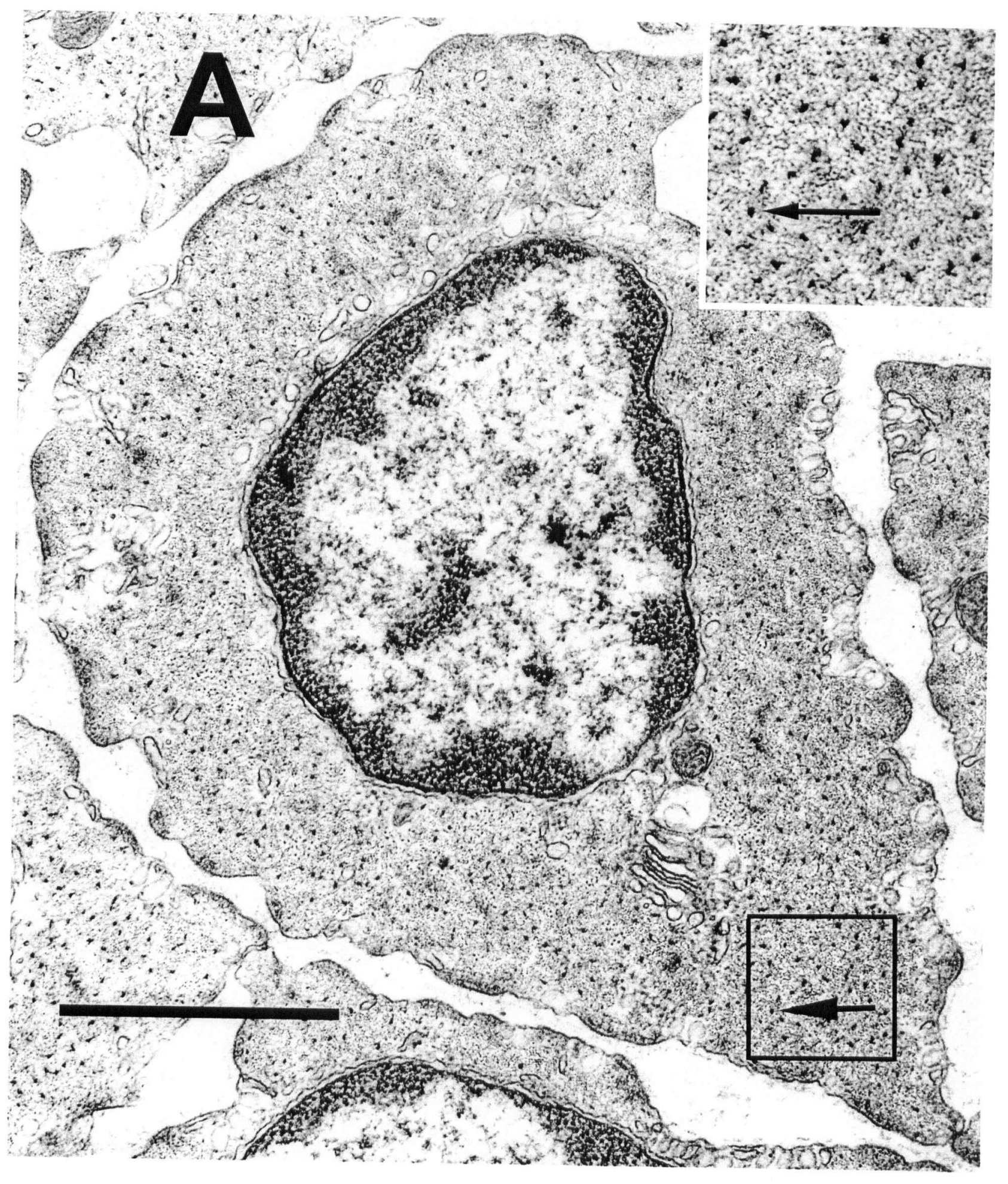

Fig 7-A. Selected examples of electron micrographs of trachealis cell cross-sections. Muscle preparation fixed at Time 1 (control) as described in Fig. 5. Arrows indicate myosin thick filaments (surrounded by actin thin filaments). Calibration bar represents 1 $\mu \mathrm{m}$. 


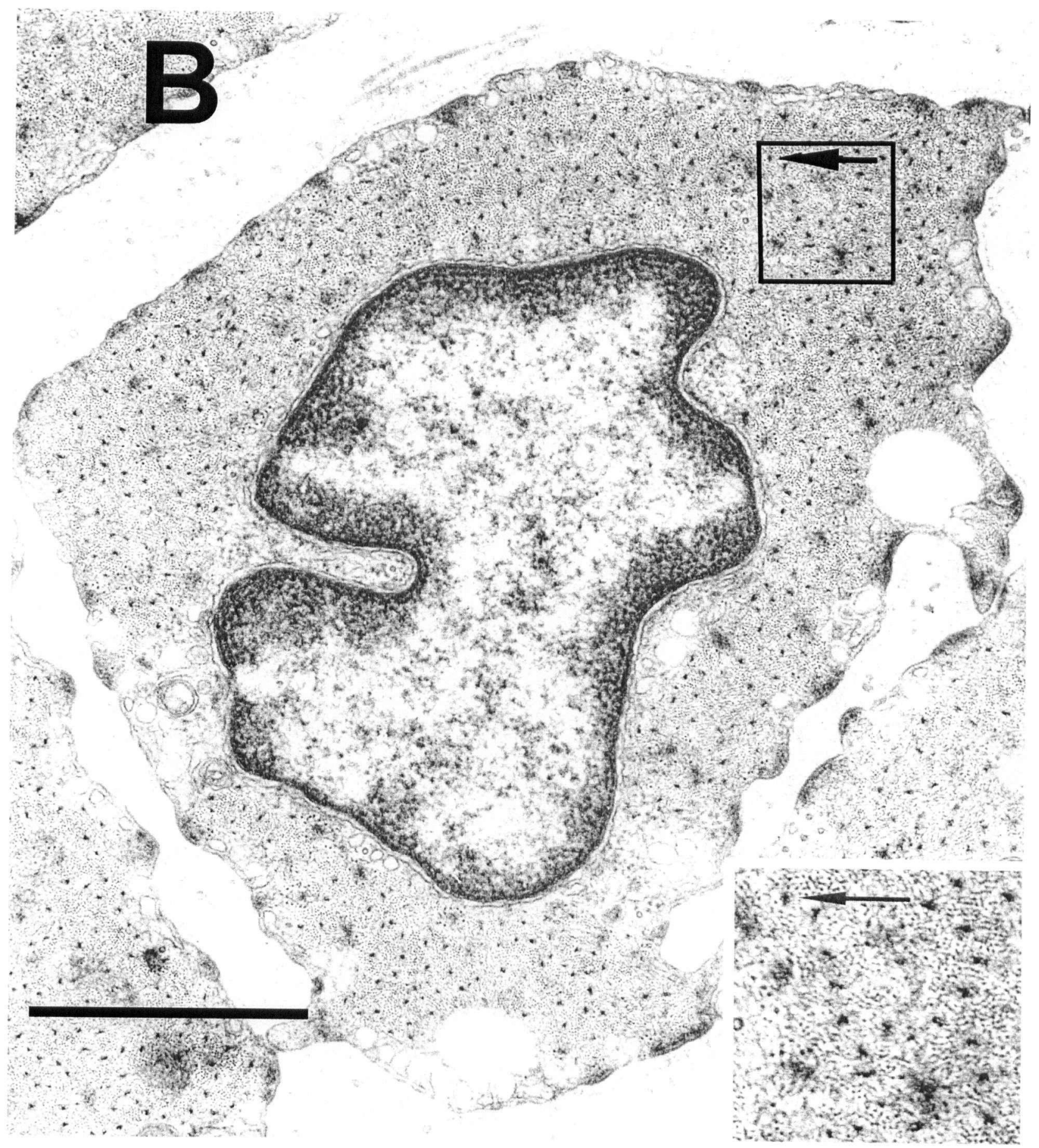

Fig 7-B. Selected examples of electron micrographs of trachealis cell cross-sections. Muscle preparation was fixed at Time 4 as described in Fig. 5. Arrows indicate myosin thick filaments (surrounded by actin thin filaments). Calibration bar represents $1 \mu \mathrm{m}$. 


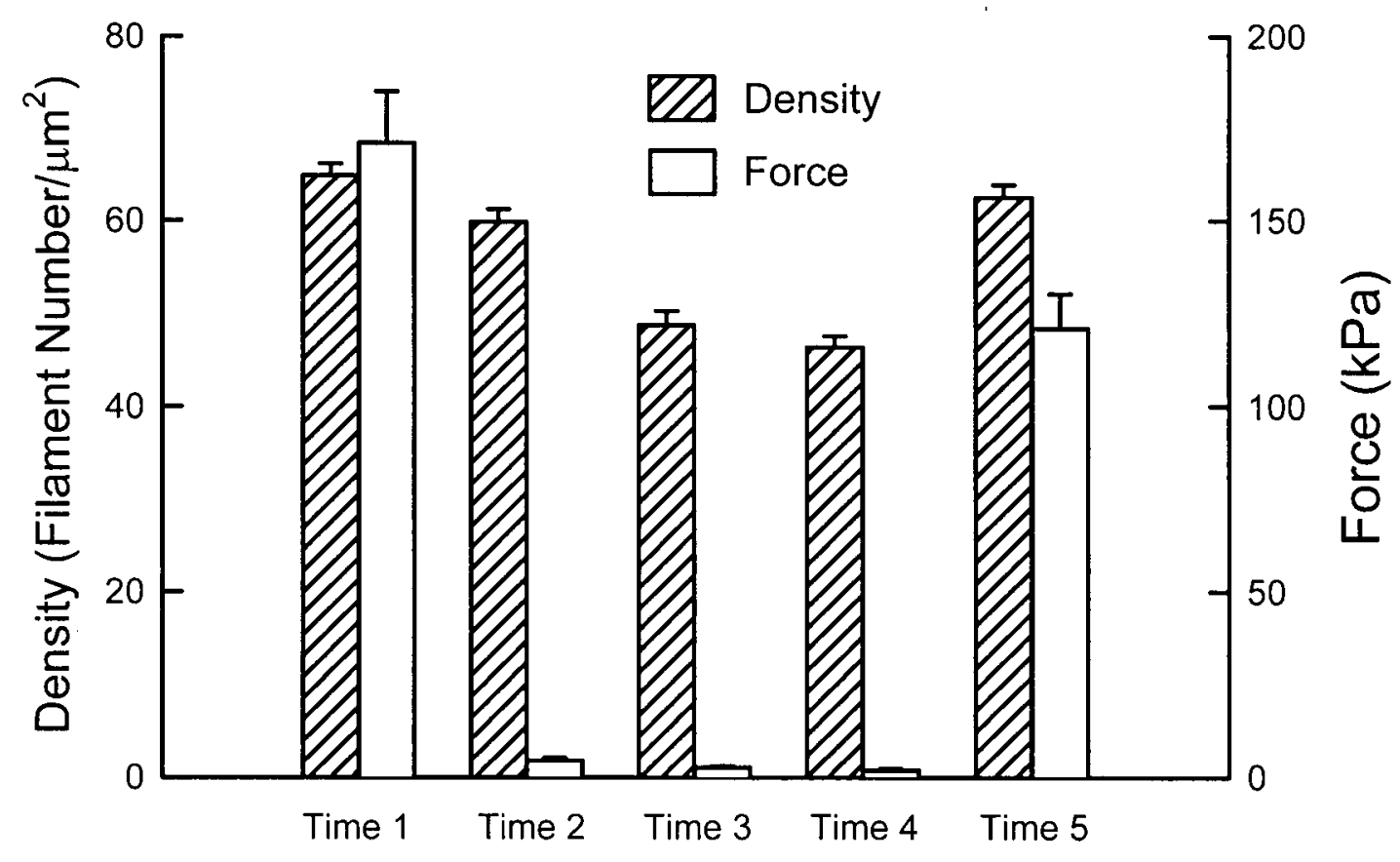

Fig 8. Thick filament density and isometric force of muscle preparations fixed at the 5 time points described in Fig. 5. Means and S.E.M. are plotted. 
Table 1 Enzymes inhibited by wortmannin (From Cardenas et al review, 1998)

Enzyme

STT4

P110 $\propto$ PI-3 kinase

PI-4-kinase $\beta$

DNA-dependent protein kinase

mTOR

Myosin-light-chain kinase

VPS34 PI-3 kinase

\section{IC50 of wortmannin}

$\ln M$

$5 \mathrm{nM}$

$50 \mathrm{nM}$

200nM

$200 \mathrm{nM}^{\mathrm{a}}$

200nM

3000nM

IC50 denotes the concentration of wortmannin at which enzyme activity is inhibited by $\mathbf{5 0 \%}$.

a The IC50 of wortmannin for $\mathrm{mTOR}$ is with respect to the autokinase activity of mTOR. 
Table 2. Number of myosin thick filaments per cell cross-section and cell cross-sectional area

\begin{tabular}{|l|l|l|l|l|l|}
\hline & Time 1 & Time 2 & Time 3 & Time 4 & Time 5 \\
\hline $\begin{array}{l}\text { Thick Filament } \\
\text { Number } \\
\text { /Cell Cross-Section }\end{array}$ & $349.6 \pm 11.4$ & $315.0 \pm 10.4$ & $250.5 \pm 10.3$ & $269.3 \pm 10.0$ & $351.4 \pm 14.7$ \\
\hline $\begin{array}{l}\text { Cross-Sectional Area } \\
\left(\mu \mathrm{m}^{2}\right)\end{array}$ & $5.4 \pm 0.3$ & $5.3 \pm 0.1$ & $5.1 \pm 0.1$ & $5.9 \pm 0.1$ & $5.6 \pm 0.2$ \\
\hline
\end{tabular}

Note: The time points are indicated in Fig. 5. Means and S.E.M. are listed, $n=4$. The thick filament number per cell cross-section at Time 1,2 and 5 are not significantly different $(\mathrm{P}>0.05$, one-way ANOVA). At Time 3 and 4 there is a significant reduction $(\mathrm{P}<0.05$, one-way ANOVA) in the filament number compared to the control (Time 1). These two values (Time 3 and 4) are however not different from each other. Variations in cell cross-sectional area are not significant $(\mathrm{P}>0.05$, one-way ANOVA). 


\section{Reference:}

1. Abbas H.K. and Mirocha J. (1988) Isolation and purification of a hemorrhagic factor (wortmannin) from fusarium oxysporum (N17B). Appl. Environ. Microbiol. 54: $1268-1274$

2. Abdel-Latif A.A. (2001) Cross talk between cyclic nucleotides and polyphosphoinositide hydrolysis, protein kinases, and contraction in smooth muscle. Exp. Biol. Med. 226(3): $153-163$

3. Adelstein R.S. and Klee C.B. (1981) Purification and characterization of smooth muscle myosin light chain kinase. J. biol. Chem. 256: 7501 - 7509

4. Aksoy M.O., Williams D., Sharkey E.M., and Hartshorne, D.J. (1976) A relationship between $\mathrm{Ca} 2+$ sensitivity and phosphorylation of gizzard actomyosin. Biochem. Biophys. Res. Commun. 69: $35-41$

5. Bagby R.M. Organization of contractile/cytoskeletal elements. (1983) In Biochemistry of Smooth Muscle. N. L. Stephens, editor. CRC Press Inc., Boca Raton, Florida. 1-84

6. Baggiolini, M., Dewald, B., Schnyder, J., Ruch, W., Cooper, P. H., and Payne, T. G. (1987) Inhibition of the phagocytosis-induced respiratory burst by the fungal metabolite wortmannin and some analogues. Exp. Cell Res. 169: 408 - 418 
7. Brian P.W., Curtis P.J., Hemming, H.G., and Norris, G.L.F. (1957) Wortmannin, an antibiotic produced by penicillium wortmannin. Trans. Br. Mycol. Soc. 40: 365 $-368$

8. Burdyga T.V. and Wray S. (1998) The effect of inhibition of myosin light chain kinase by wortmannin on intracellular $\left[\mathrm{Ca}^{2+}\right]$, electrical activity and force in phasic smooth muscle. Pflügers Arch-Eur J Physiol. 436:801-803

9. Burdyga T.V. and Wray S. (1999) The relationship between the action potential, intracellular calcium and force in intact phasic guinea-pig uteric smooth muscle. $J$ Physiol 520:867-883

10. Burke E.P., Gerthoffer W.T., Sanders K.M, and Publicover N.G, (1996) Wortmannin inhibits contraction without altering electrical activity in canine gastric smooth muscle. Am. J. Physiol. 270: C1405-C1412

11. Chacko S., Conti M.A and Adelstein R.S. (1977) Effect of phosphorylation of smooth muscle myosin on actin activation and Ca2+ regulation. Proc. Natl. Acad. Sci. U.S. 74: $129-133$

12. Choi J.K. (1962) Electron microscopy: Fifth international congress on electron microscopy Vol 2, M-9 Academic Press, New York 
13. Cooke P.H. and Fay F.S. (1972) Correlation between fiber length, ultrastructure, and length-tension relationship of mammalian smooth muscle. J. Cell. Biol. 52: $105-116$

14. Cooke P.H, and Fay F.S. (1972) Thick filaments in contracted and relaxed mammalian smooth muscle cells. Exp Cell Res 71:265-272.

15. Craig R, Smith R, and Kendrick-Jones J. (1983) Light-chain phosphorylation controls the conformation of vertebrate non-muscle and smooth muscle myosin molecules. Nature 302: 436-439

16. Devine C.E. and Somlyo A.P. (1971). Thick filaments in vascular smooth muscles. J. Cell. Biol. 49: 636-649

17. Elliot G.F. (1964) X-ray diffraction studies on striated and smooth muscles. Proc. Roy. Soc. London, Series B, 160: 467

18. Fischer E. (1944). Vertebrate smooth muscle. Physiol. Rev. 24:467

19. Flicker P., Walliman T and Vibert P. (1981) Location of regulatory light chains in scallop myosin. Biophys. J. 33: 279a 
20. Ford L.E., Seow C.Y, and Pratusevich V.R. (1994) Plasticity in smooth muscle, a hyposthesis. Can J. Physiol. Pharmacol. 72: 1320-1323

21. Fredberg J.J, Inouye D.S, Mijailovich S.M, and Butler J.P. (1999) Perturbed equilibrium of myosin binding in airway smooth muscle and its implication in bronchospasm. Am J Respir Crit Care Med 159:959-967.

22. Garamvölgyi N, Vizi E.S, and Knoll J. (1971) The regular occurrence of thick filaments in stretched mammalian smooth muscle. J Ultrastruct Res 34:135-143.

23. Garamvölgyi N, Vizi E.S, and Knoll J. (1973) The site and state of myosin in intestinal smooth muscle. Phil Trans R Soc Lond B 265:219-222

24. Gillis J.M, Cao M.L, and Godfraind-De Becker A. (1988) Density of myosin filaments in the rat anococcygeus muscle, at rest and in contraction. II. J Muscle Res Cell Motil 9:18-28

25. Godfraind-De Becker A, and Gillis J.M. (1988) Analysis of the birefringence of the smooth muscle anococcygeus of the rat, at rest and in contraction. I. J Muscle Res Cell Motil 9:9-17 
26. Guerriero, V. Jr., Russo, M.A., Olson, N.J., Putkey, J.A. and Means, A.R. (1986) Domain organization of chicken gizzard myosin light chain kinase deduced from a cloned cDNA. Biochemistry 25: $8372-8381$

27. Gunter T.E, Gunter K.K, Sheu SS and Gavin CE. (1994) Mitochondrial calcium transport: physiological and pathological relevance. Am. J. Physiol. 267 (Cell Physiol. 36): C313-C339

28. Hathaway D.R and Haeberle J.R. (1985) A radioimmunoblotting method for measuring myosin light chain phosphorylation levels in smooth muscle. Am J Physiol 249:C345-C351

29. Herrera A.M, Kuo K.H, and Seow C.Y. (2002) Influence of calcium on myosin thick filament formation in intact airway smooth muscle. Am J Physiol 282; c310 $-\mathrm{c} 316$.

30. Himpens B., Missiaen L, and Casteels R. (1995) $\mathrm{Ca}^{2+}$ homeostasis in vascular smooth muscle. J. Vasc. Res. 32: $207-219$

31. Horowitz A, Trybus K.M, Bowman D.S, and Fay F.S. (1994) Antibodies probe for folded monomeric myosin in relaxed and contracted smooth muscle. $J$ Cell Biol 126(5): 1195-1200 
32. Horowitz A, Menice C.B, Laporte R, and Morgan K.G. (1996) Mechanisms of smooth muscle contraction. Physiological Reviews. 76 (4): 967-1003. Review

33. Huxley A.F. (1980) The muscular dystrophies. Future prospects. British Medical Bulletin. 36(2):199-200

34. Ikebe M., Onishi H. and Watanabe S. (1977) Phosphorylation and dephosphorylation of a light chain of the chicken gizzard myosin molecule. $J$. Biochem. 82: $299-302$

35. Ikebe M., Stepinska M., Kemp B.E., Means A.R. and Hartshorne D.J. (1987) Proteolysis of smooth muscle myosin light chain kinase. Formation of inactive and calmodulin-independent fragments. J. Biol. Chem. 262: $13828-13834$

36. Jakes R., Northrop F. and Kendrick-Jones J. (1976) Calcium binding regions of myosin regulatory light chains. FEBS lett. 70: 229-234

37. Josephs R. and Harrington W.F. (1966). Studies on the formation and physical chemical properties of synthetic myosin filaments. Biochemistry, 5, 3474-3487

38. Josephs R. and Harrington W.F. (1968). On the stability of myosin filaments. Biochemistry, 7, 2834-2847 
39. Kamm K.E., and Stull, J.T. The function of myosin and myosin light chain kinase phosphorylation in smooth muscle. Annu. Rev. Pharmacol. Toxicol 25: 593-620, 1985

40. Kelly R.E., and Rice R.V. (1969). Ultrastructural studies on the contractile mechanism of smooth muscle. J. Cell Biol. 42: 683-694

41. Kendrick-Jones J. and Scholey J.M. (1981). Myosin-linked regulatory system. $J$. Muscle Res. Cell Motil. 2: $347-372$

42. Kendrick-Jones J., Jakes R, Tooth P.J., Craig R. and Scholey J.M. (1982) Role of myosin light chains in the regulation of contractile activity. In Basic biology of muscles: a comparative approach (ed. B.M. Twarog, R. J. C. Levine \& M. M. Bewey), pp. 255 - 272. New York: Raven Press.

43. Kendrick-Jones J., Cande W.Z., Tooth P.J, Smith R.C, and Scholey J.M. (1983) Studies on the effect of phosphorylation of the $20,000 \mathrm{Mr}$ light chain of vertebrate smooth muscle myosin. J. Mol. Biol. 165: $139-162$

44. Kendrick-Jones J., Smith R.C, Craig R., and Citi S, (1987) Polymerization of vertebrate non-muscle and smooth muscle myosins. J. Mol. Biol. 198: 241-252 
45. Klemke R.L, Cai S, Giannini A.L, Gallahger P.J, de Lanerolle P. and Cheresh D.A. (1997) Regulation of cell motility by mitogen-activated protein kinase. $J$ Cell Biol 137: $481-492$

46. Kuo K.H, Wang L, Paré P.D, Ford L.E, and Seow C.Y. (2001) Myosin thick filament lability induced by mechanical strain in airway smooth muscle. $J \mathrm{Appl}$ Physiol 90:1811-1816.

47. Lowy J., Poulsen F.R. and Vibert P.J. (1970) Myosin filaments in vertebrate smooth muscle. Nature 225: 1053 - 1054

48. Mitchell R.W, Seow C.Y, Burdyga T, Maass-Moreno R, Pratusevich V.R, Ragozzino J, and Ford L.E. (2001) Relationship between myosin phosphorylation and contractile capability of canine airway smooth muscle. $J$ Appl Physiol $90: 2460-2465$

49. Nakanishi S., Kakita S., Takahashi I., Kawahara K., Tsukuda E., Sano T., Yamada K., Yoshida M., Kase H. and Matsuda Y. (1992) Wortmannin, a microbial product inhibitor of myosin light chain kinase. J. Biol. Chem. 267 (4): $2157-2163$ 
50. Needham D.M., and Shoenberg C.F (1964) Proteins of the contractile mechanism of mammalian smooth muscle and their possible location in the cell. Proc R Soc Lond $B$ 148:517-524

51. Onish H., Suzuki H., Nakamura K., Takahashi K. and Watanabe S. (1978) Adenosine triphosphatase activity and "Thick Filament" formation of chicken gizzard myosin in low salt media. J. Biochem. $83,835-847$

52. Onishi H., and Wabakayashi T. (1982) Electron microscopic studies of myosin molecules from chicken gizzard muscle I: The formation of the intramolecular loop in the myosin tail. J Biochem 92:871-879

53. Onishi H, Wabakayashi T, Kamata T, and Watanabe S. (1983) Electron microscopic studies of myosin molecules from chicken gizzard muscle II: The effect of thiophosphorylation of the 20K-Dalton light chain on the ATP-induced change in the conformation of myosin monomers. J Biochem $94: 1147-1154$

54. Osamu H., Kaoru H., Toshiaki K. and Michio U. (1996) Inhibitory effect of wortmannin on phosphatidylinositol 3-kinase-mediated cellular events. J. Lipid Mediators Cell Signalling 14: $259-261$

55. Persechini A, Kamm K.E, and Stull J.T. (1986) Different phosphorylated forms of myosin in contracting tracheal smooth muscle. J Biol Chem 261: 6293-6299 
56. Poulsen F.R., Lowy J., Cooke P.H., Bartels E.M., Elliott G.F. \& Hughes R.A. (1987) Diffuse X-ray scatter from myosin heads in oriented synthetic filaments. Biophys. J. 51, $959-967$

57. Pratusevich V.R, Seow C.Y, and Ford L.E. (1995) Plasticity in canine airway smooth muscle. J Gen Physiol 105:73-94

58. Qi D, Mitchell R.W, Burdyga T., Ford L.E., Kuo K-H., and Seow C.Y. (2002) Myosin light chain phosphorylation facilitates in vivo myosin filament reassembly after mechanical pertubation. Am. J. Physiol. (In Press)

59. Satoshi N, Shingo K. Isami T. Kiyotaka K. Eiji T. and Tomoyuki S. (1992) Wortmannin, a microbial product inhibitor of myosin light chain kinase. $J$ Biol Chem 267(4): 2157-2163

60. Scholey J.M., Taylor K.A, and Kendrick-Jones J. (1980) Regulation of nonmuscle myosin assembly by calmodulin-dependent light chain kinase. Nature (Lond.) 287: $233-235$

61. Scholey J.M., Taylor K.A, and Kendrick-Jones J. (1981) The role of myosin light chains in regulating actomyosin interactions. Biochimie (Paris). 63: 255 - 271 
62. Seow C.Y, Pratusevich V.R, and Ford L.E. (2000) Series-to-parallel transition in the filament lattice of airway smooth muscle. $J$ Appl Physiol 89:869-876

63. Small V.J., and Sobieszek A. (1980) The contractile apparatus of smooth muscle. Int. Rev. Cytol. 64: $241-306$

64. Sobieszek A, and Small V.J. (1976). Myosin-linked calcium regulation in vertebrate smooth muscle. J. Mol. Biol. 102: 75 - 92

65. Somlyo A.P, Devine C.E, Somlyo A.V, and Rice R.V. (1973). Filament organization in vertebrate smooth muscle. Phil Trans R Soc Lond B 265:223-229

66. Somlyo A.V., Buttler T.M, Bond M., and Somlyo A.P. (1981). Myosin filaments have non-phophorylated light chains in relaxed smooth muscle. Nature (Lond). 294: $567-569$

67. Stein R.C. (2001) Prospects for phosphoinositide 3-kinase inhibition as a cancer treatment. Edocrine-Related Cancer. 8: 237 - 248

68. Suzuki H, Onishi H, Takahashi K, and Watanabe S. (1978) Structure and function of chicken gizzard myosin. J. Biochem. 84: 1529-1542 
69. Suzuki H., Kamata T., Onishi H. and Watanabe S. (1982) Adenosine triphosphate-induced reversible change in the conformation of chicken gizzard myosin and heavy meromyosin. J. Biochem. 91, 1699-1705

70. Takayama M.S., Takizawa H., Ozaki, and Karaki H. (1994) Effect of wortmannin on cytosolic $\mathrm{Ca}^{2+}$ level and force in vascular smooth muscle (Abstract). Jpn. J. Pharmacol. 64:216P

71. Trybus K.M. Huiatt T.W. Lowey S. (1982) A bent monomeric conformation of myosin from smooth muscle. Proc. Natl. Acad. Sci. U.S. A.. 79(20): 6151-6155

72. Trybus K.M, and Lowey S. (1984) Conformational states of smooth muscle myosin: Effects of light chain phosphorylation and ionic strength. J Biol Chem 259: $8564-8571$

73. Trybus K.M. and Lowey S. (1987) Assembly of smooth muscle myosin minifilaments: effects of phosphorylation and nucleotide binding. J. Cell Biol. 105 (6 Pt 2): $3007-3019$

74. Vibert P. and Craig R. (1982) 3D-reconstruction of thin filaments decorated with a $\mathrm{Ca}^{2+}$-regulated myosin. J. molec. Biol. 157, $299-319$ 
75. Vincent S.G, Cunningham P.R, Stephens N.L, Halayko A.J, and Fisher J.T. (1997) Quantitative densitometry of proteins stained with coomassie blue using a Hewlett Packard Scanjet scanner and Scanplot software. Electrophoresis 18:67-71

76. Wang L, Paré P.D, and Seow C.Y. (2000) Effects of length oscillation on the subsequent force development in swine tracheal smooth muscle. $J$ Appl Physiol $88: 2246-2250$

77. Watanabe M, Takemori S, and Yagi N. (1993) X-ray diffraction study on mammalian visceral smooth muscle in resting and activated states. $J$ Muscle Res Cell Motil 14:467-475

78. Wiesinger D., Gubler H.U., Haefliger W., and Hauser D. (1974) Antiinflammatory activity of the new mould metabolite 11- desacetoxywortmannin and of some of its derivatives. Experientia 30,135 - 136

79. Xu J.Q, Gillis J.M, and Craig R. (1997) Polymerization of myosin on activation of rat anococcygeus smooth muscle. J Muscle Res Cell Motil 18:381-393

80. Yamboliev I.A, Wiesmann K.M, Singer C.A, Hedges J.C, and Gerthoffer W.T. (2000) Phosphatidylinositol 3-kinase regulate ERK and p38 MAP kinase in canine colonic smooth muscle. Am J Physiol 279:C352-C360 
81. Yousufzai S.Y, Gao G and Abdel-Latif A.A. (2000) Mitogen-activated protein kinase inhibitors suppress prostaglandin $\mathrm{F}_{2 \alpha}$-induced myosin light chain phosphorylation and contraction in iris sphincter smooth muscle. Eur $J$ Pharmacol 407:17-26 